\title{
European Journal of Education
}

Special Issue: On becoming a teacher: a lifelong process

Volume 46, Issue 4, pages 566-580, December 2011

DOI: $10.1111 / \mathrm{j} .1465-3435.2011 .01501 . x$

Article first published online: 22 NOV 2011

\section{Engaging with Higher Education Academic Support: a first year student teacher transition model}

\author{
Sorrel Penn-Edwards \& Sharn Donnison
}

\section{Keywords:}

First Year Experience; transition; engagement; pre-service teacher education

\begin{abstract}
The need for a redefinition of first year experience in higher education is advocated with the aid of two models, which, although focused on a sample of Australian pre-service teaching students, is proposed as generalisable across the first year. Introduction to the mores of higher education is generally supported by teaching institutions during Orientation days and into the first few weeks of study on the assumption that students are then prepared for academic study. Institutions have invested significantly in providing a range of resources and services to support this process but their effectiveness relies on their timely and appropriate use by students. It is proposed that first year students' transition be identified as the FYST, a unique and important experience and the first of a series of transitions that occur throughout tertiary study. It is also argued that student engagement should be explicitly linked to critical points in the academic programme. Student teacher focus group feedback suggests that Timely, Individualised, and Prioritised Survival [TIPS] support may be key to aiding students' transition to higher education and valuable to student retention.
\end{abstract}

\section{Introduction}

We have been teaching first year university students for a number of years as well as holding the formal position of First Year Advisor which provides a one-stop support point for first year students. Our particular interest is in the academic arena that encourages students to realise their full learning potential. This includes assisting them to engage (i.e. active involvement) with academic resources and services such as developing their academic skills through online formative programmes and consulting with writing tutors. Although few institutions fail to offer academic support (McInnes, 2003), significant numbers of students do not avail themselves of these opportunities in their first year (Australian Council for Educational Research (ACER)), 2010; Harvey, Drew, \& Smith, 2006). Failing to take advantage of such support is a factor in first-year student attrition (Tinto, 2006-2007).

The project reported here was motivated by concerns to enhance first-year transition in higher education, and in particular, to identify students' use (or not) of institutional and academic support. This is identified by ACER (2010, p. 4) as one of the influential aspects of overall student engagement. Underpinning the study is a belief that attention should not only be directed to what support should be provided, but whether its method of provision (how) and timeliness (when) coincide with students' needs. 
Our combined experience of 34 years as tertiary teachers, as well as informal course and institutional student feedback and the literature (Harvey et al., 2006; Risquez, Moore, \& Morley, 2007-2008) indicate that students' academic needs (wanting to use, if not truly engage with, academic support) seem to be largely determined by critical periods in the academic calendar, such as the preparation of classwork and assessment items. Indeed, such items are often planned to compel students' use of academic resources and services. Thus, it seemed a starting point for our exploration of the prevailing apparent lack of student engagement with academic support to verify our understandings of the phenomena and provide a framework for further work in this area.

As the first step in researching this concern, we hypothesised models of student transition framed by critical points in the academic calendar and linked to proposed types of student engagement. Discussion with student teacher focus groups led to a reconceptualisation and refinement of the models which we assert help in defining the First Year Experience. These are identification of the first-year students' transition as a unique first stage in a series of transitions that occur throughout tertiary study and a model presenting student engagement types during this transition that are explicitly linked to academic stages of study (Figure 1). These models can be used, not only to inform institutions and first-year staff, but also as a means of stimulating student reflection on their own transition journey.

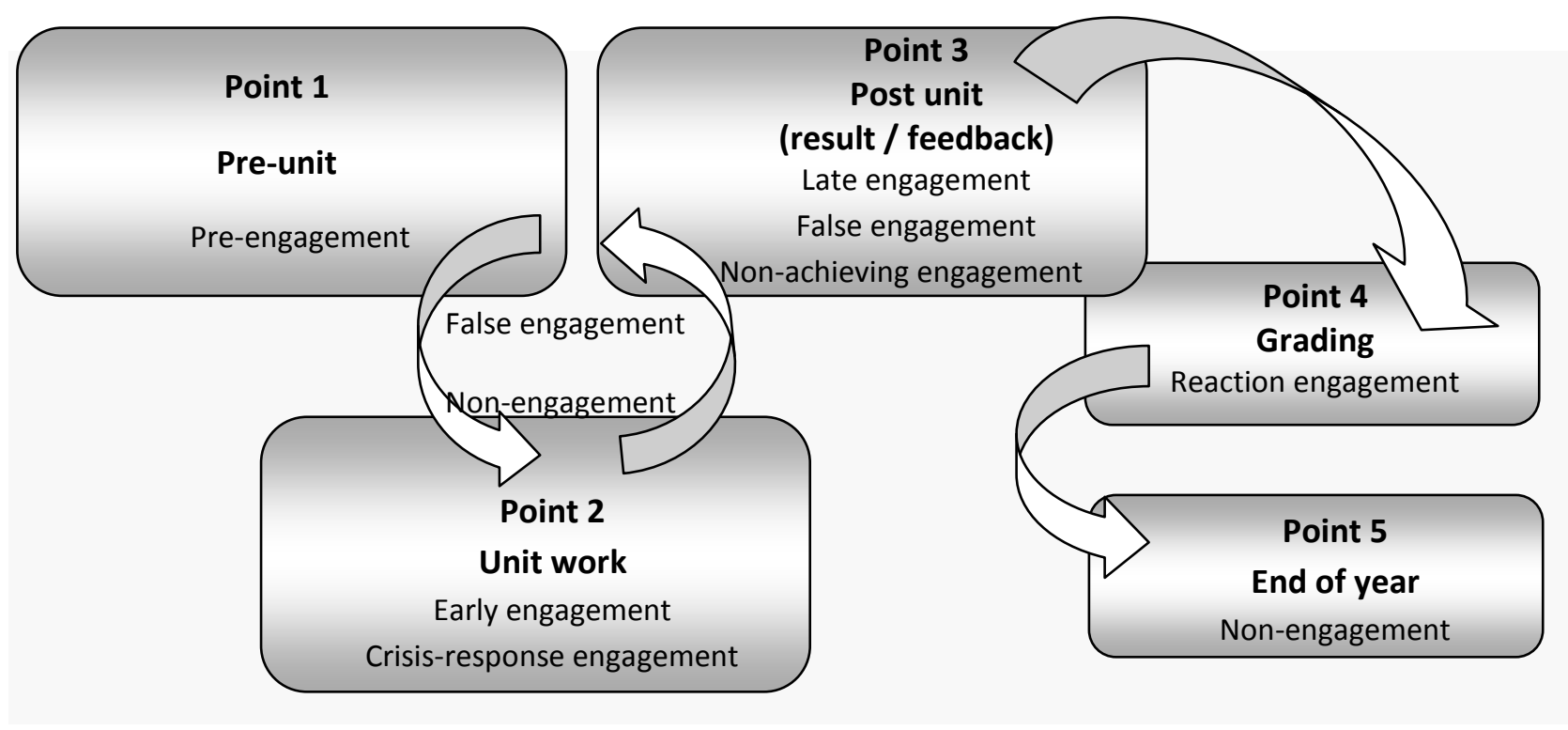

Figure 1. Cycle of academic support engagement in higher education

\section{Student Engagement and Academic Support in Higher Education}

Lack of engagement in academic studies leading to student withdrawal from tertiary studies, particularly in the first year of study, continues to be an area of concern and ongoing research for Australian and international higher education institutions. Tinto $(2005$, p. 1) observes that $47 \%$ of American students do not complete their tertiary studies and that $56 \%$ leave during their first year. Currently, about $72 \%$ of Australian students complete their degree programme (ACER, 2010, p. 51). However, ACER (2010) also notes that, in 2009, in Australian higher education, 'nearly a third of all students (30.1\% in first year and $29.9 \%$ in later-year) consider leaving their institutions before graduation' (p. x). This is slightly lower than the 2008 figures of 34.5\% and 31.6\% respectively. Higher education institutions acknowledge that student attrition is costly, particularly in relation to 
government and Commonwealth higher education funding policies. For the wider public, the cost is articulated in terms of the loss of valuable material and financial resources, and for the students, it is related to their career and life chances (Harvey et al., 2006; Yorke \& Longden, 2004, p. 6).

Research into student retention highlights the importance of motivation in the learning process (ACER, 2010; Meyer \& Turner, 2006; Reeve, 2005). However, this is not all that is required to be a successful learner. Tinto (2004) suggests that such conditions as expectations, support, feedback, involvement (engagement), and learning promote 'student persistence' (p. 2) and are key to retention. ACER (2010) also acknowledges that student engagement is dependent on participatory practices, as well as on 'institutions and staff generating conditions that stimulate and encourage involvement' (p. 4).

Tertiary institutions worldwide recognise this and have devoted significant expenditure to provide institutional academic support, i.e. not just instructional resources, but direct and indirect guidance and opportunity to assist students to engage in their studies and enhance the quality of their academic work (Braxton \& Hirschy, 2004; Commission for Academic Support in Higher Education, 2009; Tinto, 2006-2007). These strategies are mostly directed at 'closing the gap between the knowledge and academic skills that students bring with them and the requirements of the university' (McInnis \& James, 2004, p. 44). This assistance is formally offered during a student's induction period, mostly through official orientation periods, and integrated with course requirements or as supporting resources and services throughout the Post-Orientation teaching semester.

\section{Orientation and Pre-Orientation}

Induction in Australia is centred on Orientation programmes and is generally considered to occur during the first day or few days of the week prior to semester one commencement. Traditionally, it has been an administrative time for students to become familiar with university procedures, faculty programmes, and individual subjects and, while critical in the transitioning of first year students, is often experienced as confusing and overwhelming. Harvey et al. (2006) report on numerous successful Australasian and North American measures to improve students' experiences of orientation and the first weeks of semester. These focus less on gaining institutional and programme of study knowledge and more on students' immediate social and academic needs, such as facilitating staff/student and student/student relationships and acquiring academic, study, information literacy, communication, and teamwork skills. Jolley (2004) reports on one such orientation programme at Deakin University. It includes sessions on course content and assessment requirements, library and IT classes, return-to-study sessions and a mentoring programme. The mentoring programme, which encourages positive academic relationships and addresses students' immediate academic needs (Jolley, 2004, p. 4), is particularly successful.

Harvey et al. (2006), however, are silent on pre-orientation measures to assist in first year transition, although such support is not uncommon. For example, Keenan (2009) reports on a web-based programme developed by the School of Design, Engineering and Computing at Bournemouth University, UK. The Stepping Stones $2 H E$ programme asks students to prepare readings and meaningful activities prior to their first days at university. To encourage early peer bonding, students are asked to use these materials with their classroom peers and to develop shared outcomes. This programme has proven successful in relieving student anxiety, reducing information overload during orientation events, and encouraging students to reflect on their learning.

A further initiative is to offer first year university courses to early career decision high school seniors. Such programmes are common throughout North America and Lehigh University 
(Pennsylvania, USA) offers such a programme. The Clipper project is a web-based programme of study that aims to 'reach out' to incoming students and help them begin their transition to college (Bishop \& White, 2007, p. 2). Students complete numerous first year courses while completing their senior year of High School. Ongoing research on the project has found that academic preengagement has had a significant impact on retention, academic performance, social adjustment, personal-emotional balance, and attachment, although concerns were raised about the feasibility of seniors participating in the programme, given the demand on their time by their senior curriculum (Bishop \& White, 2007, pp. 369-372). Many Australian institutions offer similar programmes allowing high achieving year 12 students the opportunity to take a no risk university course whilst still at secondary school (Griffith University GUESTS Program, 2010; University of Queensland Enhanced Studies Program, 2010). If they are successful in passing the course it articulates into tertiary credits and raises their entry score; if unsuccessful, it does not penalise them in any way.

It is now widely understood that such initiatives that are offered pre- and during orientation have a beneficial effect on student adjustment and transition, especially if induction is gradual, is linked to the student's programme of study, and includes student's active involvement (Harvey et al., 2006, p. 76).

\section{Post-Orientation}

Other successful transition strategies have included extending orientation over the first weeks of semester. This is particularly successful in relieving early information overload and helping students to slowly adjust to academic demands. First year seminars, particularly in the US, are used to extend orientation and transition and commonly include lecture-based instruction on academic skill development and study techniques (Kuh et al., 2008, pp. 58-59). Such seminars are becoming increasingly popular in Australian universities. For example, the Faculty of Education at Griffith University has instituted first year seminars called Common Time across numerous programmes of study to facilitate staff/student, student/student interactions and relationships, and to develop academic and intellectual development (Fowler \& Zimitat, 2008).

Many first year academic support resources and services focus on skill development, assuming that some students lack the appropriate skill set required for academic success. Students' (perceived) lack of literacy and numeracy skills, in particular, and more recently information technology skills, have become a major focus in the first year of higher education. Support such as Common Time and first year seminars pay particular attention to this, although all higher education institutions have one or more measures in place to assist students with their multiple literacy needs. These include formalised learning support, writing and referencing workshops, bridging subjects, courses, programmes and web-based tools to enhance student learning and skill development (Ebert, O'Brien, \& Edwards, 2006; Youl et al., 2006). Harvey et al. (2006) suggest that 'learning skills development is best contextualised and embedded in the curriculum rather than taught as stand-alone courses or workshops' and that skills support should build on students' individual strengths rather than be based on perceived student needs (p. 88). While they say that first year seminars have a 'positive effect on student persistence by improving student academic and social integration' (Harvey et al., 2006, p. 73), their success is also arguably dependent upon active student involvement and most importantly engagement.

While efforts to provide academic support resources and services are commendable, Billett (2004) argues that their effectiveness is often hampered by the students themselves who do not avail themselves of these services. Even Kuh (2005) advises: 'Do not assume first-year students will use the programs and services offered to encourage their involvement' (p. 102). Upcraft, Gardner, and 
Barefoot (2005) dismiss the belief that 'if we can only get first-year students through the first six weeks of college, we considerably increase their likelihood of success' as a myth (p. 6). They say that 'there is considerable evidence that first-year initiatives should extend throughout the entire first year' (p. 6), whilst pre-eminent Australian researchers Krause, Hartley, James, and McInnis (2005, p. 89) argue that transition is achieved when students have 'adapt[ed] to university life and learning', i.e. they are productively engaged with most of the aspects of being a tertiary student (Hillman, 2005, p. 1) and are achieving successful learning and assessment outcomes.

\section{Models of First Year Transition}

Models of first year transition are the subject of many research papers. They focus on capturing the holistic first year experience from Tinto's (1975) early A Conceptual Schema for Dropout from College to the more recent Path Diagram of Conceptual Model with Commitment to the Welfare of the Student, Institutional Integrity and Communal Potential as Antecedents to Social Integration, Subsequent Institutional Commitment and Subsequent Persistence by Braxton and Hirschy (2004); the Framework for Student Transition and Retention by Lawrence (2005); and the U-Curve Theory of Adjustment by Risquez, Moore, and Morley (2007-2008). The latter describes the transition experience in four stages: honeymoon, as the name suggests, a period of interest in the new environment not threatened by assessment deadlines; culture-shock, when academic requirements become urgent; and for students who successfully manage their courses, adjustment and mastery. This model in particular underpins our study which explores why first year pre-service teaching students do not engage with institutional academic support (resources and services).

\section{The Study}

This study was conducted in 2008 using a mixed-method design identified by Plano Clark and Creswell (2008, p. 22) as a 'design with multilevel use of approaches' which strengthens its research results. It was conducted in two steps. The first involved a simple form of Prediction-Hypothesis research theory where two models were developed depicting our understanding of: (1) transition points during a higher education study programme and (2) critical stages of student engagement with the academic support offered by the university in the first year of study in alignment with types of student engagement. The second step involved focus groups with first year students in their second semester of an undergraduate pre-service teaching programme in a metropolitan Queensland university. 36 first year students, of whom $80 \%$ were female (which is representative of the programme gender statistics), were involved. The study received ethical clearance from the university and participants were assured of anonymity, with responses being coded. The task of the focus groups was to comment on the model and the typology of student engagement from a student perspective. The audio transcripts of the discussions were analysed, finding key themes of transition, engagement, and academic support. The student responses provided confirmation of the proposed models and stimulated refinements.

\section{Step 1. Developing a Typology of Engagement and Models of Transition and Critical Stages of Engagement with Academic Support}

The purpose of the initial step of this project was to conceptualise models of student transition and engagement with institutional academic support. The research on transition in higher education is generally premised on an understanding that it occurs during the first six weeks. This orientation period, recommended by Tinto (1988) over 20 years ago, is still much in favour with the majority of support opportunities being offered in the first six weeks of the first semester. However, even 20 years ago, Tinto (1988) did suggest that it was preferable that orientation activities should continue 
over the first semester (p. 451). More recent work encourages orientation through the entire first year of study (Upcraft, Gardner, \& Barefoot, 2005, p. 6), suggesting that first year transition can be a much lengthier process than six weeks.

We proposed that the first year student transition, usually only referred to generically, be labelled FYST, in keeping with the commonly used acronyms of FYE (First Year Experience) and FYS (First Year Student), and be identified as the first stage in the series of transitions that occur throughout tertiary study. Our concern is the transition experience, not persistence per se, although a good transition experience is seen as instrumental in the persistence of first year students (Kuh, 2002). As reenrolment is at the end of first year, it is not typically included in the literature on transition, which is predominately centred on the first year of study. However, reenrolment in further years of study is a focus of studies of student persistence. Indeed, in Nora, Barlow and Crisp's (2005) Student/Institution Engagement Model Theoretical Framework (p. 131), persistence is described as 'Reenrollment in Higher Education Institution'. It is not explicitly seen as a transition in line with first year transition. We suggest that this element of persistence in tertiary study be also seen as part of a continuous process of 'transition' to new experiences and that transition is a cyclical process where students 'transition' into further years of study (The Quality Assurance Agency for Higher Education, 2008, p. 35) and finally into their professional work environments or postgraduate studies (Figure 2).

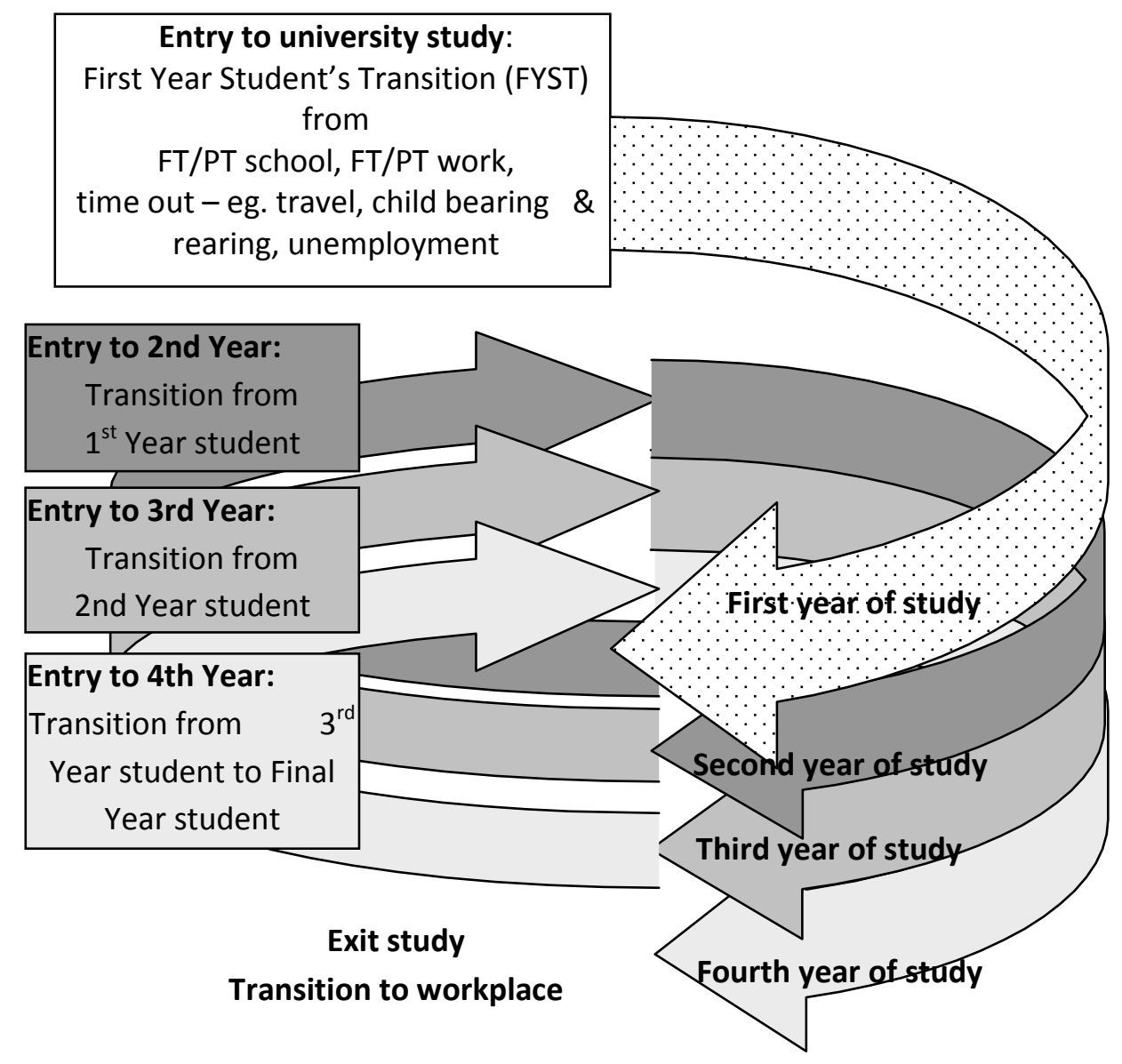

Figure 2. Spiral of transition in higher education studies

During the FYST stage we conceptualised engagement with academic resources and services as an active process linked to assessment tasks, specifically: (i) seeking to understand academic 
requirements (task, aims, format), (ii) preparation (reading, finding resources, outlining and drafting assignments), (iii) having an awareness and use of resources (literacy help, library databases), (iv) submitting assignments which met format and task requirements; and (v) self-reflection on and evaluation of skills, knowledge and ability. It was also surmised that engagement with academic support may not be uniform and that there were five critical points for use of resources and services which were tied to the academic calendar, predominately to enrolment and assessment dates in first year (Figure 3 ). This assumption was based on an understanding of engagement types and our experiences as first year advisers and teachers in first-year subjects.

\section{Acceptance of}

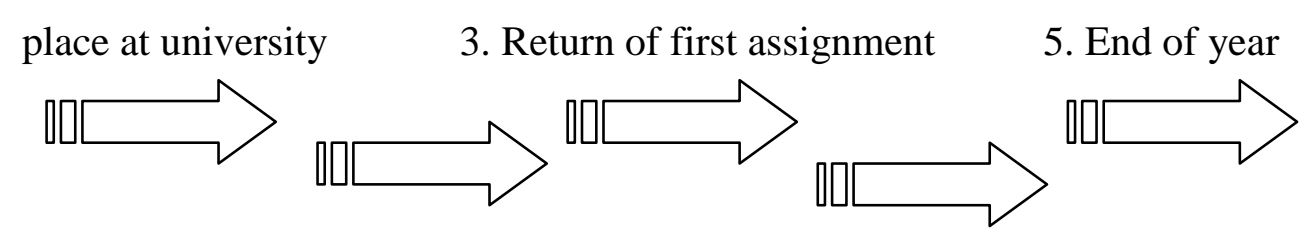

2. Orientation week $\quad$ 4. End of semester

Figure 3. Critical points for academic support engagement

It was acknowledged that not all students engage in their studies in the same way. Some engage in transition processes early in the academic year by identifying their literacies needs during the first few weeks at university; others do not recognise and address their needs until critical stages of their programme. Hence, we developed a typology of student engagement with institutional support:

- pre-engagement — active post-enrolment, pre-orientation (aiming for active university learning experience);

- early engagement - active post orientation;

- crisis engagement - active only in last-minute reaction to deadlines;

- late engagement - active only as a reaction to the first feedback and marks;

- false engagement - a stage of realisation that previous engagement was not fully active;

- non-achieving engagement - active but not achieving well;

- reaction engagement - active as a reaction to final course grades etc; and

- non-engagement - those who are not active.

A model, Critical Points for Academic Support Engagement and Stages of Engagement (Figure 4) that aligned critical points with the typology of engagement with institutional academic support was intended to inform and stimulate the discussions of the student focus groups in step 2 of the study. 

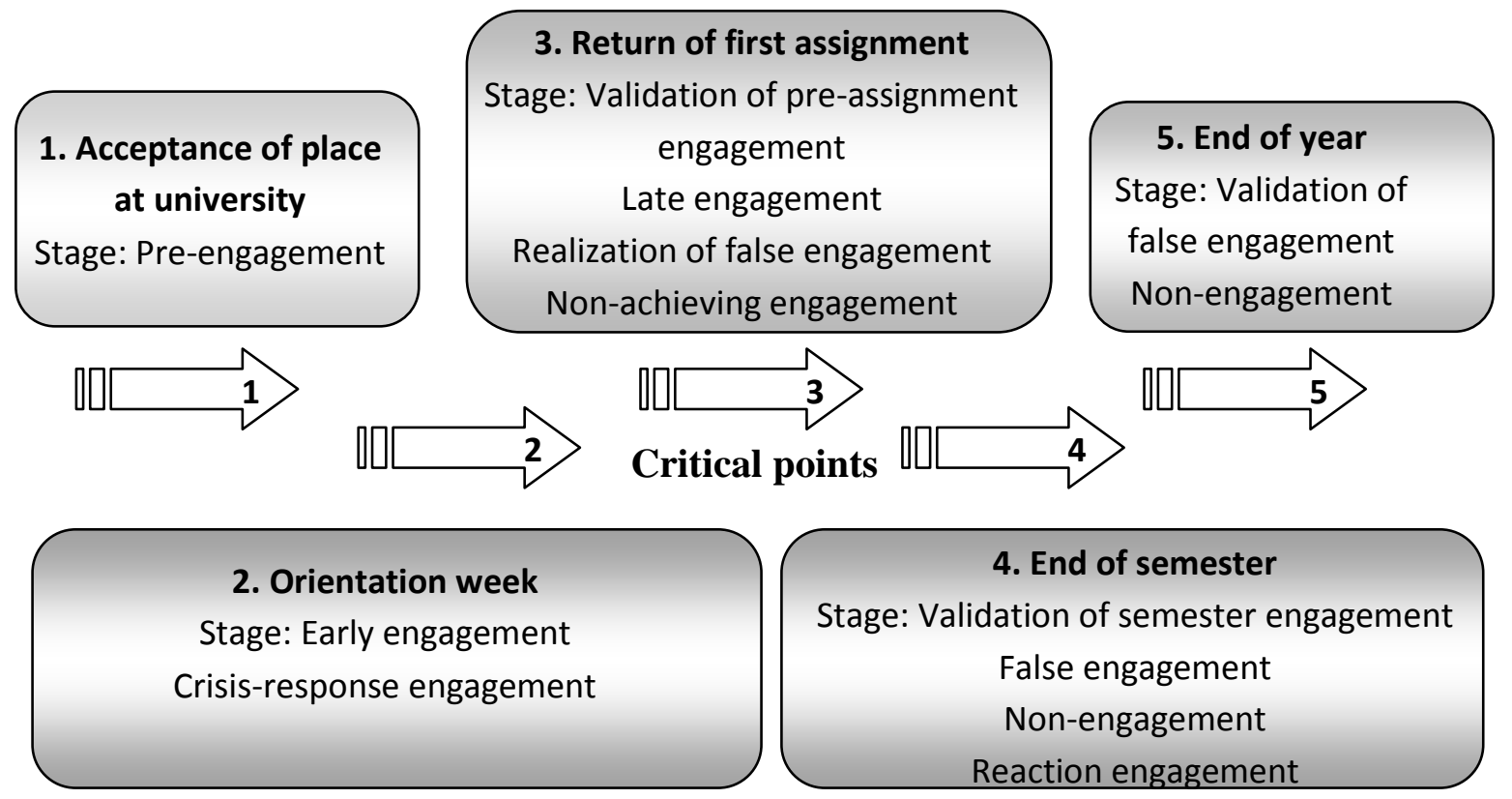

Figure 4. Critical points for academic support engagement and stages of engagement

\section{Step 2. Focus group discussions}

Three focus groups were held with 36 first-year students in their second semester of a Bachelor of Education (Secondary) programme. They were asked about their experience as first-year students as related to transitioning ('becoming a uni student') and engagement ('being involved with study'). They were then asked to comment on the Spiral of Transition in Higher Education Studies (Figure 2) and the Critical Points for Academic Support Engagement and Stages of Engagement (Figure 3) models; particularly on the proposed types of engagement with academic support. Examples of questions asked by the focus group facilitator were:

- Do you recognise these kinds of involvement/engagement?

- Do you think that these points in the semester are critical points for becoming a university student/transition?

- Can you think of other critical transition points?

- Do you think that the above points are good ways of identifying types of involvement/engagement?

The focus groups were audio recorded and transcribed; individuals were not identified. The responses were considered with respect to the dominant key themes of transition, engagement, and academic support.

\section{Transition}

Students unanimously believed that transition extended beyond the first six weeks of semester. They also reflected that entering the second semester had been a time of transition, albeit different from entering first semester, and they expected to experience further challenges upon entering subsequent years. They noted that transition was an ongoing process that continued throughout the academic year, that although, 'you're more engaged and more effectively transitioned by the end of first semester . . . it's certainly not finished there. It's ongoing and you're still doing it' and suggested that, 'Orientation is that beginning phase, but the transitioning goes on'. Transition was also equated with learning, 'you don't stop learning, it's a continual thing' and it was stated that 'the whole university 
degree is a learning process, but, definitely the first year is a transition because you're getting used to the university lifestyle'. After some discussion, it was ascertained that transition was an ongoing process of continual learning, 'It's getting used to how to learn it, . . . rather than what we're learning, because that's more a continual thing . . . how to help yourself'.

Students felt that it was complicated by the fact that it was not acknowledged by all staff because 'there's always something new or they're changing something on the [course web] site, there's always something you've got to get used to'. Crucially, many felt that, 'everyone just assumes that you should know these things and they talk to you like, oh you should know this already'.

\section{Engagement}

The focus group participants also clarified their concept of engagement and commented on the models' proposed types of engagement with academic support. Students preferred to refer to engagement as an activity to achieve rather than a state of being (e.g. being an early engager). They also acknowledged that the term engagement, as used in higher education, was one they were not familiar with before learning it at university and felt that it should initially be associated with the more common term of involvement, 'because how deeply you get involved depends on your personality and then that depends on the way that you learn and the way that you feel'.

The participants proposed one new type of engagement. Active (in the sense of 'ongoing') engagement was suggested as a replacement for early engagement, as it referred to 'one who continues to look for ways of engaging, depending on what's happening . . . they're not waiting for the external things to happen to them, they're actively pursuing things'.

Several students self-identified with types of engagement sometimes with unexpected insights, such as pre-engagement may not necessarily be intrinsically motivated. To clarify, one student attended pre-orientation sessions but said, 'I didn't really want to go and then my mum was like, you should go, you're not doing anything this holidays except for working anyway, so I just went'. The groups also identified engagement, per se, as multi-engagement which is context dependent and follows a cyclical process of engagement and re-engagement, explaining that:

There's some things when we started off, I jumped the gun and went and enrolled and stuff. But there's still places where I'm dragging my feet and I'm way down here with late engagement . . . and that just depends on a lot of external factors. You're constantly re-negotiating what you know and what you think you know through the whole course, so I don't think you ever got to the point where you think, yeah I'm fully engaged, like you got a handle on it . . . Then you go onto the next thing which is a bit harder and you've got to start the process all over again because it's a new challenge or it's a new kind of assignment that you haven't done before and different dynamics.

The participants felt that all students would benefit from knowing about the types of engagement and that this could be used for reflection and self-development, particularly after the return of assignments when it could prompt use of resources and services that were previously unused. Knowing your own engagement type could be 'very helpful because it makes you more aware of your own learning style and your own proactiveness'. It was also suggested that if engagement types were linked to learner styles then students could self-diagnose, 'diagnosing tests leading to individualized reminders for each student — i.e. these are my weaknesses so I should . . .' or that student mentors could demonstrate and explain the different engagement types as 'you need someone to just sit us down and go, you're this and this is how you go about getting to the next level and bettering your studies’ and that this process should be tailored to the individual. 
The students agreed that critical points of engagement with academic support were largely related to study units and assessment with a comment emphasising the first assignment as a critical point, 'not my first assignment return but when you had all four assignments for subjects due at once'. This led to discussion about the incorporation of a mental breakdown point or week which happened at different times for different students such as 'every morning before the first assignment' or somewhere 'between orientation and first assignment returns'. Students acknowledged that in order to survive they had to prioritise what they could do and that they felt overwhelmed by information and directions, especially in the first weeks of semester. For some, choosing to engage was a conscious decision:

I do try and engage as early as I can but I don't tackle everything at once. It was just so full on from the very beginning and . . . you've just got so much coming in and then they're like, oh and you've got an assignment due, and I don't even know where the buildings are to get to my classes, let alone having an assignment due.

[It's] a conscious choice if you want to move from non-engagement to engagement. It's not as though you wake up one day and you're automatically doing it, you have to decide to do it and if you're that determined to do it, then you're going to seek out the help and not just wait for it to come to you.

\section{Academic Support}

The focus group participants acknowledged that academic support was readily available, 'there's all these places where you can go and I think as long as you're made aware of where you can go' but because of the abundance of resources and services students believed that 'realistic' (i.e. timely) prompts would increase engagement. Orientation Week was especially mentioned as a time of information overload. Students felt that reminders following this week would be appropriate as, for some, it was a time of shifting between engaging as a person and engaging as a student:

There's this shift between how was I feeling. I couldn't get into my classes because I was so worried about moving away from home and I'm so panicky about doing my first assignment that I don't really know what to do.

The students believed that information about academic support would need to link into existing student sources rather than adding a new source. They suggested that their individual home page on the online student portal would be the primary site for such information. However, as students often failed to look at anything except study materials, they felt that rather than providing another link, the information would need to be more 'in your face'.

\section{Summary of Study}

The research literature identifies that students learn and engage in different ways and our hypothesis was to locate different types of engagement with academic support on an academic timeline. The first proposed model, transition in higher education (Figure 2), features the First Year Student Transition (FYST) as a distinctive first stage in a number of transitions during a degree programme. The second model presented a typology of student engagement with academic support intrinsically linked with critical points in the academic calendar (Figure 4). Pre-service teaching student focus groups endorsed the two models only offering one alternative term, active (somewhat incorrectly used to mean 'ongoing') engagement for early engagement. Our definition of engagement is that it is active involvement (as against being a passive participant), so to avoid confusion, the original term early must be retained. However, the sentiment that engagement is an ongoing process signalled a 
need to re-conceptualise the Critical Points for Academic Support Engagement and Stages of Engagement model (Figure 4). Individuals pointed out that this form of engagement is context dependent and follows a cyclical process of engagement and re-engagement that is dependent on the requirements of each course, particularly content difficulty, activity involvement, and assessment needs. At any one time, students could be at different stages of engagement with academic support for each of their studies, for example at a stage of non-achieving engagement in a period of passive lectures in one course, early engagement in discussions of assignments, and crisis-response engagement in completing an assignment at the last minute.

Given this, it is proposed that our reconceptualised model, although ambitious in generalising from our sample, can be better represented as a model with wider application (Figure 1) where Points 1-3 form a cycle (pre-unit work, unit work, and post-unit work) which may occur several times in each course in reaction to units of study whether these be preparation for classes (research, readings, activities) or for assignment submission. Point 4 is the culmination of the study of which that unit is part and where a total mark is received which determines a grade (e.g. semester course). Point 5 is a definitive point in the degree programme, e.g. the end of first year studies.

\section{Discussion}

The reconceptualised model (Figure 1), Cycle of Academic Support Engagement in Higher Education, considers academic engagement with institutional resources and services as a new process for many students. As such, it is in line with Rogers' (2003) diffusion (adoption) of innovation theory where 'diffusion is a special type of communication concerned with the spread of messages perceived as new ideas' (p. 35). He theorised that the adoption of a process will take the following five steps: 'an individual passes from first knowledge of an innovation, to forming an attitude toward the innovation, to a decision to adopt or reject, to implementation of the new idea, and to confirmation of this decision' (p. 170). Furthermore, Rogers proposes that this knowledgepersuasion-decision sequence may, in some sociocultural settings, with certain innovations, 'occur frequently' (p. 179) and repetitively. Using Rogers (2003), it is possible to understand student engagement with academic support, not as an either-engaged-or-not situation but rather a process where students first need to gain knowledge of available resources and services, then develop an attitude towards them, utilise or reject them, and finally, reflect upon and confirm their decision to adopt the support offered.

Whether students have knowledge of, and are persuaded to adopt an academic support is, according to our experience and our student focus group data, dependent on its timely offering. Many higher education resources and services operate as if student engagement with them is uniform and occurs at the same time. Many are offered at set times within the semesters while some are ongoing throughout the semester but are only introduced at set times. Some first year resources and services are offered only within first semester and may be clustered around the first few weeks.

However, in terms of academic support, our data indicate that students do not operate on a semester or yearly cycle but on a smaller cycle, by study unit needs (preparation, activities, and assessment) and access academic resources and services as they need them. This engagement is highly individualised and occurs at different levels and at different times. They will also revisit resources and services at different levels as they need them. Arguably, therefore, the most effective ways to encourage adoption of academic support is to firstly, provide more flexible timing and secondly prompt student use of them at appropriate times and in an individualised and prioritised manner, that is, to offer Timely, Individualised, and Prioritised Survival [TIPS] support. The purpose of this acronym is supported by Tinto (2006-2007, p. 10) who defines actions that are effective and 
enduring as 'tipping points'. TIPS support is predominately a scaffolding system, setting up an individualised foundation of general academic skills and resources and non-academic support services for each student. TIPS also role-models to students the need to prioritise organisation and as such it has the potential to improve retention, not only in the first year but in the entire study programme by helping students to survive the transition period. This is to be discussed in a forthcoming paper that will report on the development and trialling of a TIPS resource, the UniNavigator.

\section{Application and Further Action}

Further action is predicated on the acceptance that student engagement with academic support is a complex reiterative cycle and that students' transition to tertiary studies, that is the attainment of engagement, is ongoing. The reality of higher education is that many study programmes are assessed summatively early in the first semester, a decided disadvantage for those not engaging early. Consequently, many students not achieving well at this initial stage give up and 'drop out' hence affecting programme retention. Formal acknowledgement of a flexible First Year Student Transition (FYST) period and of a cyclic typology of student engagement would allow recognition of what students have achieved rather than what they have not, by honestly saying 'it's OK to have engaged late'. To support this action the Spiral of Transition in Higher Education Studies model (Figure 2) and the Cycle of Academic Support Engagement in Higher Education model (Figure 1) are offered for discussion with a view to informing the planning of teaching practice for the first year. In particular, this is of importance for first semester subject Convenors and First Year Advisors. For academics and students, these models may also stimulate reflection and discussion on types of engagement with academic support and the nature of transition and other relevant concerns. Such a discussion is to be carried out with the 2010 first year students in the same programme and extended for use with students in other first year programmes. When used as a reflection stimulus with different cohorts and programmes it is expected to refine the model further.

\section{NOTE}

1. We gratefully acknowledge the funding received from a University Teaching and Learning Grant, which allowed us to carry out this project, and to the colleagues and reviewers who provided constructive criticism on this article.

\section{REFERENCES}

Australian Council for Educational Research (2010) Doing More for Learning. Enhancing Engagement and Outcomes. Australasian Survey of Student Engagement. Australasian Student Engagement Report (Camberwell, Victoria, Author). http://ausse.acer.edu.au/images/docs/AUSSE_2009_Student_Engagement_Report.pdf

Billett, S. (2004) Workplace participatory practices: conceptualising workplaces as learning environments, Journal of Workplace Learning, 16, pp. 312-324. http://www.emeraldinsight.com.libraryproxy.griffith.edu.au/products/journals/journals.htm?id $=j w l$

Bishop, M. \& White, S. (2007) The Clipper Project: exploring whether early engagement through web-based instruction can help ease high school students' college transition, Journal of College Student Retention, 9, pp. 357-376. doi: 10.2190/CS.9.3.f

Braxton, J. M. \& Hirschy, A. S. (2004) Reconceptualizing antecedents of social integration in student departure, in: M. Yorke \& B. Longden (Eds) Retention and Student Success in Higher 
Education (Berkshire, England, Society for Research into Higher Education \& Open

University Press), pp. 89-102.

Commission for Academic Support in Higher Education (2009) Home page.

http://www.myacpa.org/comm/academic/index.cfm

Ebert, P. R., O'Brien, M. \& Edwards, W. (2006) Using online collaboration to personalise the first year experience and actively engage students in their education. Paper presented at the First Year in Higher Education 2006 Conference: Engaging Students. http://www.fyhe.com.au/past_papers/2006/Papers/Ebert.pdf

Fowler, J. \& Zimitat, C. (2008) Common Time: embedding the concept of academic and social integration across cognate degree programmes, Innovations in Education and Teaching International, 45, pp. 37-46. doi: 10.1080/14703290701757435

Griffith University (2010) Griffith University GUESTS Program. http://www.griffith.edu.au/admissions/undergraduate-admissions/other-pathways-togriffith/guests-program

Harvey, L., Drew, S. \& Smith, M. (2006) The First-Year Experience: a review of literature for the higher education academy (York, UK, The Higher Education Academy).

Hillman, K. (2005) The First Year Experience: the transition from secondary school to university and TAFE in Australia. Longitudinal surveys of Australian youth. Research Report 40. ACER and the Australian Government Department of Education, Science and Training (DEST) (Camberwell, Victoria, Australia, The Australian Council for Educational Research). http://www.lsay.edu.au/lsay pubs/research/LSAY_lsay40.pdf

Jolley, D., Callaghan, V. \& Emmitt, M. (2004) First Year at Deakin: a university-wide effort, in: 8th Pacific Rim First Year in Higher Education Conference Proceedings, 14-16 July 2004, Melbourne, Victoria. http://www.fyhe.com.au/past_papers/Papers04/046.doc

Keenan, C. (2009) Stepping Stones 2HE: fresh thinking for introducing PDP to freshers (Hospitality, Leisure, Sport and Tourism Network, Enhancing Series, Student Centred Learning). http://www.heacademy.ac.uk/assets/bmaf/documents/publications/Case_studies/Keenan_bourn emouth_SC_v3_edited.doc

Krause, K., Hartley, R., James, R. \& Mcinnis, C. (2005) The First Year Experience in Australian Universities: findings from a decade of national studies (Melbourne, Victoria, Centre for the Study of Higher Education, University of Melbourne).

http://www.dest.gov.au/sectors/higher_education/publications_resources/profiles/first_year_ex perience.htm

Kuh, G. D. (2002) The National Survey of Student Engagement: conceptual framework and overview of psychometric properties (National Survey of Student Engagement). http://nsse.iub.edu/html/psychometric_framework_2002.cfm

Kuh, G. D. (2005) Student engagement in the first year of college, in: M. L. Upcraft, J. N. Gardner, \& B. O. Barefoot (Eds) Challenging and Supporting the First-Year Student: a handbook for improving the first year of college (San Francisco, Jossey-Bass), pp. 86-107.

Kuh, G. D., Kinzie, J., Buckley, J. A., Bridges, B. K. \& Hayek, J. C. (2008) Piecing together the student success puzzle: research, propositions, and recommendations, ASHE Higher Education Report, 32 (Hoboken, NJ, Jossey-Bass).

Lawrence, J. (2005) Re-conceptualising attrition and retention: integrating theoretical, research and student perspectives, Studies in Learning, Evaluation, Innovation and Development, 2, 3, pp. 16-33. http://sleid.cqu.edu.au/index.php

Mcinnis, C. (2003) From marginal to mainstream strategies: responding to student diversity in Australian universities, European Journal of Education, 38, pp. 387-400.

Mcinnis, C. \& James, R. (2004). Access and retention in Australian higher education, in: M. Yorke, \& B. Logden (Eds) Retention and Student Success in Higher Education (Berkshire, England, Society for Research into Higher Education \& Open University Press), pp. 32-45. 
Meyer, D. K. \& Turner, J. C. (2006) Re-conceptualizing emotion and motivation to learn in classroom contexts, Educational Psychology Review, 18, pp. 377-390. doi: 10.1007/s10648006-9032-1

Nora, A., Barlow, E. \& Crisp, G. (2005) Student persistence and degree attainment beyond the first year in college: the need for research, in: A. Seidman (Ed) College Student Retention: Formula for Student Success (Westport, CT, Praeger), pp. 129-153

Plano Clark, V. L. \& Creswell, J. W. (Eds) (2008) The Mixed Methods Reader (Thousand Oaks, CA, Sage).

Reeve, J. M. (2005) Understanding Motivation and Emotion (4th ed) (New York, Wiley).

Risquez, A, Moore, S. \& Morley, M. (20072008) Welcome to college? Developing a richer understanding of the transition process for adult first year students using reflective written journals, Journal of College Retention, 9, pp. 183-204. http://www.baywood.com/journals/previewjournals.asp?id=1521-0251

Rogers, E. M. (2003) Diffusion of Innovation (5 ${ }^{\text {th }}$ ed) (New York, Free Press).

The Quality Assurance Agency for Higher Education (2008) Quality Enhancement Themes: the first year experience. Transition to and during the first year. http://www.enhancementthemes.ac.uk/documents/firstyear/Transition\%20-\%20Final.pdf

Tinto, V. (1975) Dropout from higher education: a theoretical synthesis of recent research, Review of Educational Research, 45, pp. 89-125.

Tinto, V. (1988) Stages of student departure: reflections on the longitudinal character of student leaving, The Journal of Higher Education, 59, pp. 438-455. http://www.ohiostatepress.org/Journals/JHE/jhemain.htm

Tinto, V. (2004) Promoting Student Retention through Classroom Practice. http://www.staffs.ac.uk/access-studies/docs/Amster-paperVT(2)L.doc

Tinto, V. (2005) Rethinking the First Year of College. http://hakatai.mcli.dist.maricopa.edu/fsd/c2006/docs/rethinkfirstyearcollege.pdf

Tinto, V. (20062007) Research and practice of student retention: what next? Journal of College Student Retention, 8, pp. 1-19. http://www.baywood.com/journals/previewjournals.asp?id=1521-0251

University of Queensland (2010) University of Queensland Enhanced Studies Program. http://www.uq.edu.au/study/update/?page $=91374$

Upcraft, M. L., Gardner, J. N. \& Barefoot, B. O. (2005) Preface, Introduction, in: M. L Upcraft, J. N. Gardner \& B. O. Barefoot (Eds) Challenging and Supporting the First-Year Student: a handbook for improving the first year of college (San Francisco, Jossey-Bass), pp. xi-xxx, 112.

Yorke, M. \& Logden, B. (2004) Retention and Student Success in Higher Education (Berkshire, England, Society for Research into Higher Education \& Open University Press).

Youl, D. J., Read, J. R., George, A. V. \& Schmid, S. (2006) Bridging Courses: good learning environments for engaging students? Paper presented at the First Year in Higher Education 2006 Conference: Engaging Students.

http://www.fyhe.qut.edu.au/past_papers/2006/program.html 